\title{
First-principles Study of Elastic and Surfaces Properties of $\Omega$ (Al2Cu) Phase
}

\author{
Bao-Shu QIAN, Yan-Hui HOU*, Bo-Si LI, Liang MIN and Yang LIU \\ The State Key Laboratory of Refractories and Metallurgy, Wuhan University of Science \\ and Technology, Wuhan, 430081, P.R. China \\ "houyanhui@wust.edu.cn
}

Keywords: First-principles, Surface properties, Elastic properties, Electronic structure.

\begin{abstract}
Elastic and surface properties of $\Omega$ phase have been studied by using the first-principles calculations based on density functional theory. The elastic properties results show that $\Omega$ structures are more inclined to resist shear deformation than volume deformation, and the precipitation of $\Omega$ phase enhances the strength of the alloy, but reduces the ductility of the alloy. The surface relaxation, surface energy, and the corresponding electronic structure are calculated and analyzed to reveal surface properties of $\Omega$ phase. The calculated results are in accordance with the experiment results and calculated results of others, which provide theoretical reference for further practical applications of the alloys.
\end{abstract}

\section{Introduction}

$\mathrm{Al}-\mathrm{Cu}-\mathrm{Mg}-\mathrm{Ag}$ alloys are promising aerospace materials because of their high strength and excellent stability at elevated temperature. For compositions with high $\mathrm{Cu}$ : $\mathrm{Mg}$ ratios, the high strength and excellent stability are attributed to precipitation of $\Omega$ phase on the $\{111\}$ aluminium matrix[1-2].The second precipitates phase properties, as well as their morphology and distribution, that essentially control the mechanical property of the alloys. The purpose of the present work is to study the elastic and surface properties of $\Omega$ phase by first-principles calculation based on density functional theory, aiming to get information about elastic constant, bulk modulus, shear modulus, Young's modulus, and Poisson's ratio of $\Omega$ phase; to get information about surface structure relaxation, surface energy and stability for different termination of (100), (010), and (001) surfaces.

\section{Methodology}

The Vienna ab initio simulation package (VASP) was used to perform all the calculations. The Perdew-Burke-Ernzerh of formulation and the generalized gradient approximation (GGA) were employed to treat the electron exchange and correlation [3-4]. A conjugate-gradient algorithm was used to relax the ions.

In order to assess the accuracy of our computational method, specifically the used pseudo potentials, we firstly performed a series of calculations on $\mathrm{Al}, \mathrm{Cu}, \theta$ structures. The results were in good agreement with experimental and calculated results of others. So the used theoretical methodology and the calculated lattice parameters are reliable.

The crystalline structure of $\Omega$ phase used in this work are the widely accepted orthorhombic structure (Fmmm, a $=0.496 \mathrm{~nm}, \mathrm{~b}=0.859 \mathrm{~nm}, \mathrm{c}=0.848 \mathrm{~nm})$ in ref [5].

\section{Elastic Prorerties}

The elastic constants were calculated by second-order polynomials fitting for different distortion energies versus their distortions. The energy of different small distortion can be expressed as [6]:

$$
E\left(V, \delta_{i}\right)=E\left(V_{0}, 0\right)+V_{0} \sum_{i=1}^{6} \sigma_{i} \delta_{i}+\frac{V_{0}}{2} \sum_{i, j=1}^{6} C_{i j} \delta_{i} \delta_{j}+\ldots
$$


The Bulk modulus, Shear modulus, Young's modulus and Poisson's ratio of Al, $\mathrm{Cu}, \theta$ and $\Omega$ structures are calculated in Table 1.

Table 1 Calculated bulk modulus B, shear modulus G, Young's modulus E, B/G, Poisson's ratio v of $\mathrm{Al}, \mathrm{Cu}, \theta$ and $\Omega$ structures

\begin{tabular}{llllll}
\hline Phase & $\mathrm{B}(\mathrm{GPa})$ & $\mathrm{G}(\mathrm{GPa})$ & $\mathrm{B} / \mathrm{G}$ & $\mathrm{E}(\mathrm{GPa})$ & $\mathrm{v}$ \\
\hline $\mathrm{Al}$ & 77.41 & 28.09 & 2.76 & 75.18 & 0.34 \\
& $71.70[9]$ & $27.20[9]$ & 2.64 & $72.40[9]$ & $0.33[9]$ \\
$\mathrm{Cu}$ & 141.39 & 49.00 & 2.89 & 131.77 & 0.34 \\
& $129.60[10]$ & $48.30[10]$ & 2.68 & $136.40[10]$ & $0.34[10]$ \\
$\theta$ & 99.36 & 42.14 & 2.36 & 110.76 & 0.31 \\
& $113.40[7]$ & $41.40[7]$ & 2.74 & $109.90[7]$ & $0.34[7]$ \\
$\Omega$ & 91.71 & 68.38 & 1.34 & 164.31 & 0.20
\end{tabular}

According to the Pugh criterion, the critical value separating ductility from brittleness is about 1.75[8].As we can see from Table 1, the precipitation of $\Omega$ phase enhances the strength of the alloy, but reduces the ductility of the alloy.

\section{Surface Properties}

There are six terminations in $\Omega$ phase: Al1 (Al2), $\mathrm{Al} 2(\mathrm{Cu}), \mathrm{Cu}(\mathrm{Al} 2)$ and $\mathrm{Al} 2(\mathrm{Al} 1)$ for (001) and (010) surface slab, $\mathrm{Al}(\mathrm{Cu}), \mathrm{Cu}(\mathrm{Al})$ for (100) surface slab. When the Al1-Al2 bond is broke, there will be two kinds of surfaces. One is the Al1 (Al2) (001) and the other is the Al2(Cu) (001)termination, where the letter in brackets represents the subsurface atom.

\section{Surface Energy and Stability}

The surface energy $\gamma_{i}$ can be calculated as follows [11]:

$$
\gamma_{i}=\frac{1}{2 S_{0}}\left[E_{\text {slab }}^{i}-N_{A l} \mu_{A l}-N_{C u} \mu_{C u}-P V-T S\right]
$$

When the different chemical potentials between the individual elements and the elements in pure bulk equals zero, $\gamma_{i}$ becomes the surface energy. The results of $\gamma_{i}$ are presented in Table 2 .

Table 2. Surface energy (in J m-2) for each termination

\begin{tabular}{|c|c|}
\hline Surface (010) & $(001)$ \\
\hline$\underset{)}{\mathrm{Al} 11}(\mathrm{Al} 2 \mathrm{Al} 2(\mathrm{Al} 1) \mathrm{Al} 2(\mathrm{Cu}) \mathrm{Cu}(\mathrm{Al} 2)$ & $\mathrm{Al}(\mathrm{A} 12) \mathrm{Al} 2(\mathrm{~A} 11) \mathrm{Al}(\mathrm{Cu}) \mathrm{Cu}(\mathrm{Al} 2) \mathrm{Cu}(\mathrm{Al})$ \\
\hline 1.63602 .1702 & 1.18741 .69391$. \\
\hline
\end{tabular}



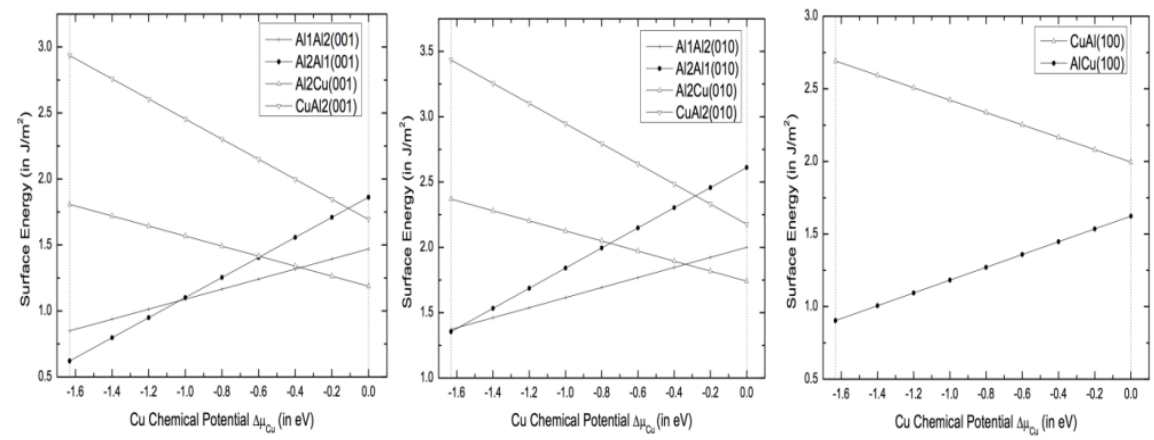

Fig.1 .Surface energy as a function of $\mathrm{Cu}$ chemical potential for (a)four termination (001) surfaces; (b) four termination (010) surfaces; (c) two termination (100) surfaces.

The surface energy of (001), (010) and (100) surfaces of $\Omega$ as a function of $\Delta \mu_{C u}$ is presented in Figure 1. It can be seen from Figure 1(a), the Al2 (Al1) (001)-termination is most stable in low $\Delta \mu_{C u}$ range. With the increase in $\Delta \mu_{C u}$, the Al1 (Al2)(001)-termination and $\mathrm{Al} 2(\mathrm{Cu})(001)$-termination become more stable. From Figure1 (b), Al1(A12)(010)-termination and Al2(Cu)(010)-termination have the least surface energy respectively in different $\mathrm{Cu}$ chemical potentials range among all terminations for (010) surface slab. From Figure 1(c), Al (Cu) (100)- termination is more stable through the whole $\Delta \mu_{C u}$ range.

\section{Surface Structure Relaxations}

The relaxation of different terminated slabs for $\Omega$ surfaces has been calculated, and the results are presented in Table 3.

Table3. Layers displacement and interlayer distance variations of different terminated slabs of $\Omega(001)$ surface:(a) A12(Cu)(001)-termination; (b) Al1(Al2) (001)-termination; (c) Al2(A11) (001)termination; (d) $\mathrm{Al}(\mathrm{Cu})(100)$-termination

\begin{tabular}{|c|c|c|c|c|c|c|}
\hline $\begin{array}{l}\text { Surfac } \\
\mathrm{e}\end{array}$ & $\begin{array}{l}(001) \\
\mathrm{Al} 2(\mathrm{Cu})\end{array}$ & $\mathrm{Al1}(\mathrm{Al} 2)$ & $\mathrm{Al} 2(\mathrm{~A} 11)$ & $\begin{array}{c}(100) \\
\mathrm{Al}(\mathrm{Cu})\end{array}$ & $\begin{array}{l}(010) \\
\text { Al1A12 }\end{array}$ & $\mathrm{A} 12 \mathrm{Cu}$ \\
\hline$\Delta \mathrm{z} 1$ & $-0.1551 \AA$ & $0.1025 \AA$ & $\overline{-}-2400 \AA$ & $-0.0457 \AA$ & $\overline{-}-3056 \AA$ & $0.0178 \AA$ \\
\hline$\Delta \mathrm{z} 2$ & $0.0324 \AA$ & $0.3475 \AA$ & $0.1490 \AA$ & $0.1096 \AA$ & $-0.0213 \AA$ & $0.0087 \AA$ \\
\hline$\Delta \mathrm{z} 3$ & $-0.0815 \AA$ & $0.0240 \AA$ & $-\overline{0.0673 \AA}$ & $0.0508 \AA$ & $\overline{0} .1640 \AA$ & - $0.0286 \AA$ \\
\hline$\Delta 12$ & $-26.26 \%$ & $-17.30 \%$ & $-27.09 \%$ & $-12.84 \%$ & $-1.04 \%$ & $0.06 \%$ \\
\hline$\Delta 23$ & $15.96 \%$ & $45.96 \%$ & $15.06 \%$ & $4.86 \%$ & $-0.07 \%$ & $0.03 \%$ \\
\hline$\Delta 34$ & $-5.68 \%$ & $3.41 \%$ & $-9.43 \%$ & $4.20 \%$ & $-0.59 \%$ & $-0.11 \%$ \\
\hline
\end{tabular}

The largest relaxation is found in the first layer for $\mathrm{Al} 2(\mathrm{Cu})(001)$-termination, $\mathrm{Al} 2(\mathrm{Al1})(001)$ termination and Al1(Al2) (010)-termination, whereas the largest relaxation of $\mathrm{Al1}(\mathrm{Al} 2)(001)$ termination and $\mathrm{Al}(\mathrm{Cu})(100)$-termination are found in the second layer, and the third layer of $\mathrm{A} 12 \mathrm{Cu}(010)$-termination has the largest relaxation. 


\section{Conclusions}

The elastic and surface properties of $\Omega$ phase have been studied by using the first-principles calculations. It is concluded that,

(1) Structures are more inclined to resist shear deformation than volume deformation. The precipitation of $\Omega$ phase enhances the strength of the alloy, but reduces the ductility of the alloy.

(2)Al2(Al1)(001)-termination, $\mathrm{All}(\mathrm{Al} 2)(001)$-termination, and $\mathrm{Al} 2(\mathrm{Cu})(001)$-termination have the least surface energy in different $\mathrm{Cu}$ chemical potentials range among all the terminations for (001) surface slab. For the terminations of (010) surface slab it is found that Al1 (Al2)(010)termination and $\mathrm{Al} 2(\mathrm{Cu})(010)$-termination have the least surface energy in different $\mathrm{Cu}$ chemical potentials range. $\mathrm{Cu}(\mathrm{Al})(100)$-termination has the less surface energy throughout the whole $\mathrm{Cu}$ chemical potentials range between the two terminations for (100) surface slab.

(3)The largest relaxation is the first layer for $\mathrm{Al} 2(\mathrm{Cu})(001)$-termination, $\mathrm{Al} 2(\mathrm{Al1})(001)$ termination and Al1(A12) (010)-termination, whereas the largest relaxation of Al1(A12)(001)termination and $\mathrm{Al}(\mathrm{Cu})(100)$-termination are found in the second layer, and the third layer of $\mathrm{Al} 2 \mathrm{Cu}(010)$-termination has the largest relaxation.

\section{Acknowledgments}

This work is supported by Erasmus Mundus Scholarships, Research Fund for the Doctoral Program of Higher Education of China (20134219120001), and Research Fund for the Returned Overseas Chinese Scholars.

\section{References}

[1] I.J. Polmear and M.J. Coupter, Design and development of an experimental wrought aluminum alloy for use at elevated temperatures, Metall. Trans. A. 19, 1027-1035(1988).

[2] M. Gazizov and R. Kaibyshev, Effect of over-aging on the microstructural evolution in an Al$\mathrm{Cu}-\mathrm{Mg}-\mathrm{Ag}$ alloy during ECAP at $300^{\circ} \mathrm{C}$, J. Alloys Compd. 527,163-175(2012).

[3] J.P. PerdewandK. Burke, Generalized Gradient Approximation Made Simple, Phys. Rev. Lett.77, 3865-3868(1996).

[4] J.P. PerdewandY. Wang, Accurate and simple analytic representation of the electron-gas correlation energy, Phys. Rev. B.45, 13244-13249(1992).

[5] K.M. Knowles and W.M. Stobbs, The Structure of $\{111\}$ age-hardening precipitates in Al-CuMg-Ag alloys, Acta Cryst.44, 207-227(1988).

[6] J.F. Nye, Physical properties of Crystals, (Oxford University Press, Oxford, 1985).

[7] J. Vallin and M. Mongy, Elastic constants of aluminum, J. Appl. Phys.35, 1825-1826(1964).

[8] S.F. Pugh, Relations between the elastic moduli and the plastic properties of polycrystalline pure metals, Philos. Mag. 45,823-843(1954).

[9] R.L. Whelchel and T.H. Sanders, Jr., Spall and dynamic yield behavior of an annealed aluminum-magnesium alloy, Scripta Mater. 92, 59-62(2014).

[10] G. Bradfield and H. Pursey, The role of preferred orientation in elasticity investigations, Phil. Mag. 44, 437-443(1953).

[11]H.Z. Zhang and S.Q. Wang, First-principles study of Ti3AC2 (A=Si, Al) (001) surfaces, Acta Mater. 55, 4645-4655(2007). 